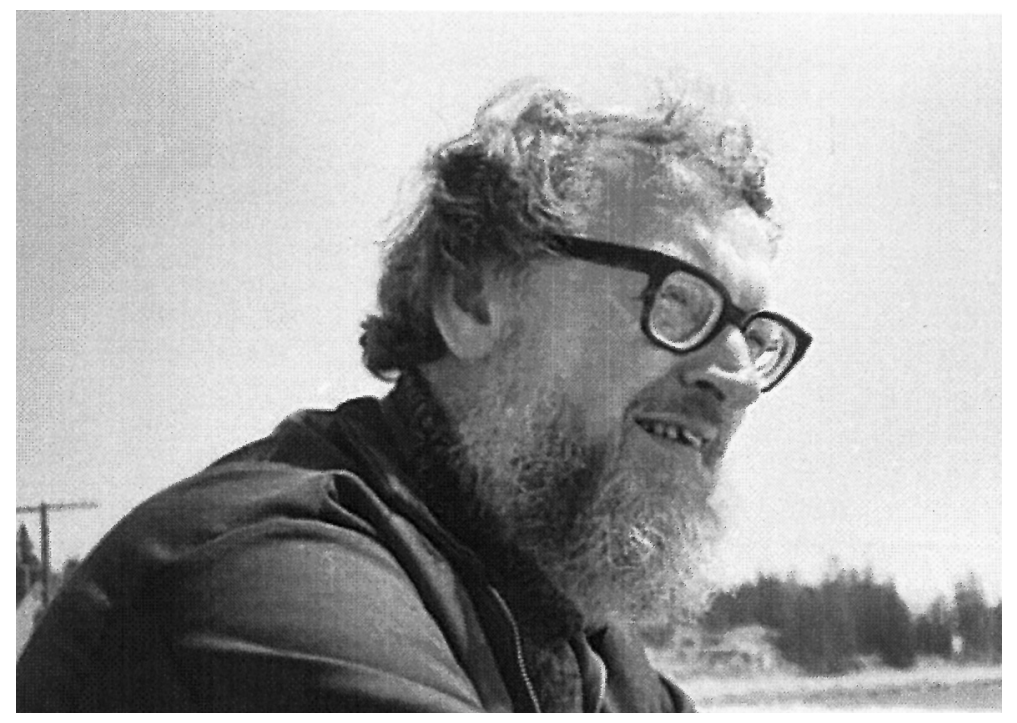

\title{
Peter Wangersky (1927-2007)
}

Peter John Wangersky passed away on January 7 , 2007 at the age of 79 after a brief bout with cancer. His wife, Eleanor, and their three sons were at his side.

Pete was born in Woonsocket, Rhode Island and spent his childhood there and in Lynn, Massachusetts. He entered Brown University in 1943 at age 16 under a wartime accelerated program, majoring in chemistry. His university career was interrupted when he was drafted into the U.S. military where he served until the end of the war. He then returned to Brown under the GI Bill to complete his undergraduate degree. After Brown, he worked briefly at the Scripps Institute of Oceanography and the U.S. Fish and Wildlife Service. He then went to Yale University for graduate studies, earning his doctorate in zoology under the polymath zoologist G. Evelyn Hutchinson, who probably was the inspiration for his own wide-ranging scientific interests. He taught briefly at the University of Miami, where he met and married Eleanor, and then at the Bingham Oceanography Laboratory at Yale University. In 1965 he accepted an offer to join the Dalhousie University Institute of Oceanography in Canada, and was joined there by Gordon Riley, who became the chairman. Under their leadership the Institute grew and evolved into a full Department of Oceanography. Pete later served two terms as chairman. He served on the Dalhousie faculty until his retirement in 1993 when he and Eleanor moved to Victoria, British Columbia, where Pete accepted an adjunct professorship at the University of Victoria.

Pete was a very broad and diverse researcher; he was a theoretical ecologist as well as a chemical oceanographer long before either of these 'interdisciplinary' fields became accepted as intellectually respectable. He published in fields as disparate as the organic chemistry of seawater, algal physiology, and mathematical modeling of population dynamics. Through his own early publications and his influence as editor, he was a main stimulus for development of the field of organic chemistry of seawater. In theoretical ecology, his paper on lag effects in population cycles, published in 1956, when he was a graduate student, is still widely cited. He also held two patents on chemostat design. He loved to go to sea and participated in numerous oceanographic cruises. Pete served as advisor to about $25 \mathrm{PhD}$ students at Dalhousie and was a friend and casual mentor to almost all of the other oceanography graduate students during his tenure. He was known for his breadth of knowledge, wisdom, willingness to help anyone seeking advice and his warm personality. 
Assisted by Eleanor, he helped to create a collegial atmosphere at the Department of Oceanography. Students, staff and friends were all invited to stop by the Wangersky home on Sunday afternoons for coffee, sweets and stimulating conversation. He was a quick and voracious reader with eclectic tastes. His favorite hobbies included photography and fishing.

In 1974 Pete took over as the second editor, from volume 2, of the journal Marine Chemistry, initially as a temporary fill-in, and then served as editor-inchief for the next twenty years. His stewardship of the journal took it from a new, relatively unproven forum, to the well-established authority that it is today. He was noted for encouraging a wide variety of research subjects and new ideas. A special issue of the journal was published in 1997, containing papers based on presentations by former students and close associates at a symposium organized in honor of his retirement.

In retirement he continued on the editorial boards of Scientia Marina (Barcelona) and Environmental Science and Pollution Research, although he gave up

\section{Selected bibliography}

(from more than 100 publications)

Wangersky, P.J. - 1952. Isolation of ascorbic acid and rhamnosides from sea water. Science, 115: 685.

Wangersky, P.J. and W.J. Cunningham. - 1957. Time lags in preypredator population models. Ecology, 38: 136-139.

Wangersky, P.J. and G.E. Hutchinson. - 1958. Manganese deposition and deep water movement in the Caribbean. Nature, 181: 108-109

Wangersky, P.J. and R.R.L. Guillard. - 1960. Low molecular weight organic base from the dinoflagellate Amphidinium carteri. Nature, 185: 689-690.

Rosholt, J.N., C. Emiliani, J. Geiss, F.F. Kozy and P.J. Wangersky.

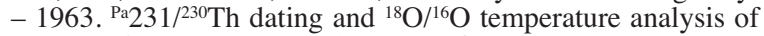
core A-254-BR-C. J. Geophys. Res., 67: 2907-2911.

Riley, G.A., P.J. Wangersky, and D.Van Hemert. - 1964. Organic aggregates in tropical and subtropical surface waters of the North Atlantic Ocean. Limnol. Oceanogr., 9: 546-550.

Wangersky, P.J. - 1965. The organic chemistry of sea water. Am. Sci., 53: 358-374.

Wangersky, P.J. - 1967. Sodium chloride content and compaction in deep-sea cores. J. Geol., 75: 332-335.

Wangersky, P.J. - 1972. The control of seawater $\mathrm{pH}$ by ion pairing. Limnol. Oceanogr., 17: 1-6.

Jenkins, W.J., M.A. Beg, W.B. Clarke, P.J. Wangersky, and H. Craig. -1972 . Excess ${ }^{3} \mathrm{He}$ in the Atlantic Ocean. Earth Planet. Sci.Lett., 16: 122-126.

Wangersky, P.J. - 1972. Evolution and the niche concept. Trans. Connecticut Acad. Arts Sci., 44: 369-376.

Wangersky, P.J. - 1976. Particulate organic carbon in the Atlantic and Pacific Oceans. Deep Sea Res., 23: 457-465.

Wangersky, P.J. - 1976. The surface film as a physical environ- similar duties for Marine Ecology Progress Series in 1998. In response to a request from Limnology and Oceanography in 1998, he volunteered to help foreign authors with English usage, and received many such calls over the years. He also organized and edited two volumes of The Springer-Verlag series "Handbook of Environmental Chemistry"; Marine Chemistry (2000) and Estuaries (2006), and served on the advisory board for the series. He was a 50-year member of Sigma Xi.

Pete was a true pioneer of many disciplines, and his mind remained active and razor-sharp, spinning off more research ideas, spanning many fields, right until his death. Oceanography, marine chemistry, and population ecology have each lost one of their most innovative and productive workers. His ashes were blended into seawater chemistry at Canadian time-series station PAPA on June 11, 2007.

\section{JONATHAN SHARP, SIFFORD PEARRE, DONALD GORDON, ERIC MILLS and CARL BOYD}

ment. Ann. Rev. Ecol. Syst., 7: 161-176.

Wangersky, P.J. - 1978. Production of dissolved organic matter. In: O. Kinne (ed.), Marine Ecology, Vol. IV. . pp. 115-220. J. Wiley and Sons, New York.

Wangersky, P.J. and C.P. Wangersky. - 1980. The Manna effect: A model of phytoplankton patchiness in a regenerative system. Int. Rev. ges. Hydrobiol., 65: 681-690.

Wangersky, P.J. - 1982. Model ecosystems: The limits of predictability. Thalassia Jugosl., 18: 1-10.

Johnson, B.D. and P.J. Wangersky. - 1985. Sea water filtration: Particle flow and impaction considerations. Limnol. Oceanogr., 30: 966-971.

Wangersky, P.J. - 1986. Biological control of trace metal residence time and speciation: A review and synthesis. Mar. Chem., 18: 269-297.

Parrish, C.C. and P.J. Wangersky. - 1987. Particulate and dissolved lipid classes in cultures of Phaeodactylum tricornutum grown in cage culture turbidistats with a range of nitrogen supply rates. Mar. Ecol. Progr. Ser., 35: 119-128.

Wangersky, P.J. - 1993. Dissolved organic carbon methods: a critical review. Mar. Chem., 41: 61-74.

Lombardi, A.T. and P.J. Wangersky. - 1995. Particulate lipid class composition of three marine phytoplankters Chaetoceros gracilis, Isochrysis galbana (Tahiti) and Dunaliella tertiolecta grown in batch culture. Hydrobiologia, 306: 1-6.

Chen, W. and P.J. Wangersky. - 1996. Production of dissolved organic carbon in phytoplankton cultures as measured by hightemperature catalytic oxidation and ultraviolet photo-oxidation methods. J. Plankton Res., 18: 1201-1211.

Dafner, E.V. and P.J. Wangersky. - 2002. A brief overview of modern directions in marine DOC studies Part II.-Recent progress in marine DOC studies. J. Environ. Monitoring, 4: 55-69. 